This item was submitted to Loughborough's Research Repository by the author.

Items in Figshare are protected by copyright, with all rights reserved, unless otherwise indicated.

\title{
Long-term performance of amorphous photovoltaic modules
}

PLEASE CITE THE PUBLISHED VERSION

PUBLISHER

(C) IEEE

VERSION

VoR (Version of Record)

LICENCE

CC BY-NC-ND 4.0

REPOSITORY RECORD

Vorasayan, Pongpan, Thomas R. Betts, Ralph Gottschalg, and David Infield. 2019. "Long-term Performance of Amorphous Photovoltaic Modules". figshare. https://hdl.handle.net/2134/5127. 
This item was submitted to Loughborough's Institutional Repository (https://dspace.lboro.ac.uk/) by the author and is made available under the following Creative Commons Licence conditions.

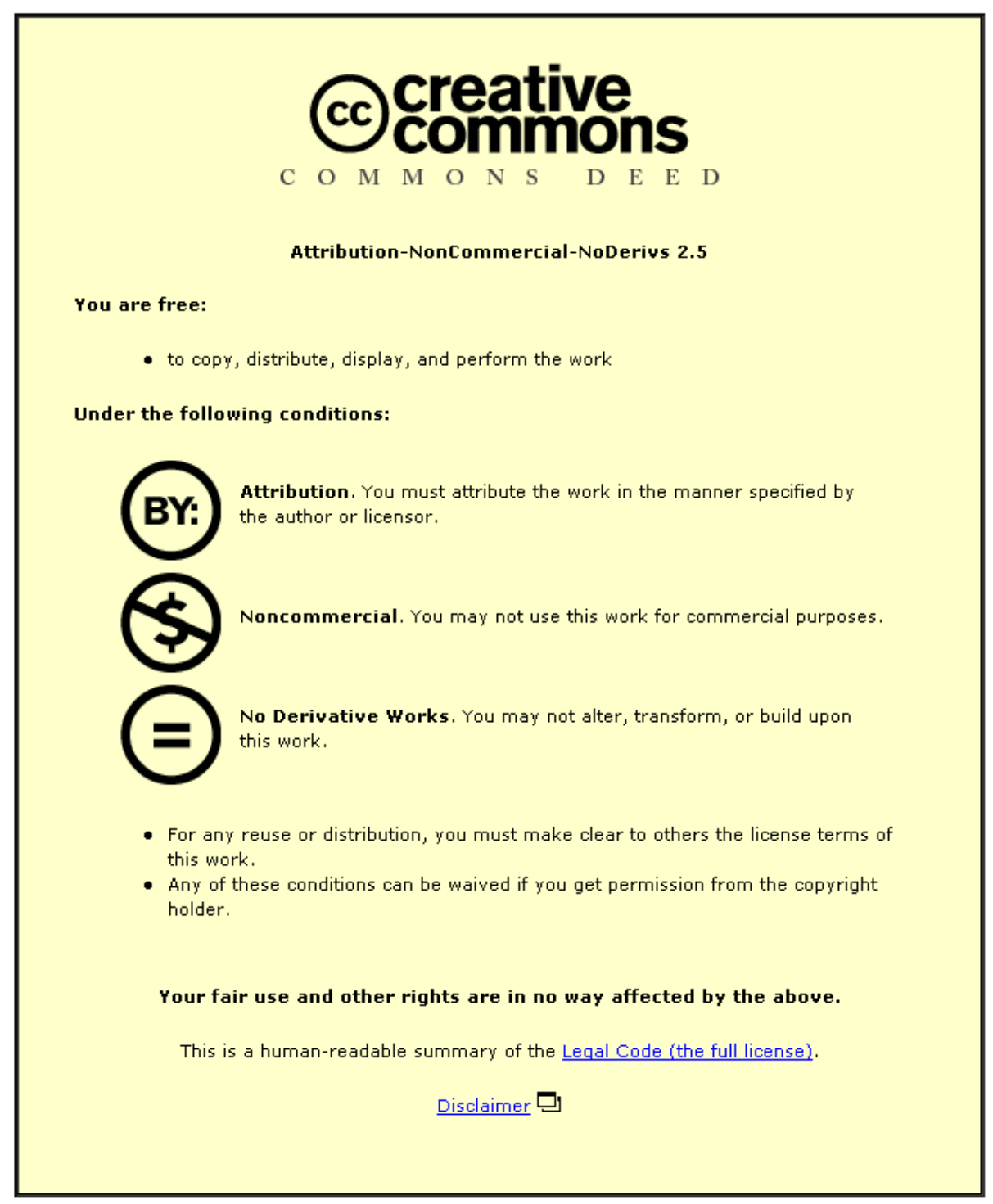

For the full text of this licence, please go to: http://creativecommons.org/licenses/by-nc-nd/2.5/ 


\title{
LONG-TERM PERFORMANCE OF AMORPHOUS PHOTOVOLTAIC MODULES
}

\author{
P. Vorasayan, T. R. Betts, R. Gottschalg ${ }^{\star}$, D.G. Infield \\ Centre for Renewable Energy Systems Technology, Department of Electronic and Electrical Engineering, \\ Loughborough University, Loughborough, LE11 3TU, United Kingdom
}

\begin{abstract}
This work aims to demonstrate the energy production of amorphous silicon devices through long-term monitoring. Some devices have a very high specific energy production while other does not accomplish this. The reasons for seasonal variations are investigated. Assuming that the short circuit current is mainly influenced by spectral changes allows degradation to be attributed to the fill factor. The seasonal variation of this is investigated in more detail, demonstrating differences between single and multi junction devices.
\end{abstract}

\section{INTRODUCTION}

Amorphous silicon (a-Si) photovoltaic devices have the potential to achieve very low energy generation costs. Often it is claimed that these devices produce more electricity than other technologies and thus result in a significant reduction of electricity generation costs. This is seen as a major advantage of this technology over conventional devices. The aim of this study is to document and verify this increased energy production. In order to achieve this, a cross-section of different technologies available in 2001/02 was obtained and installed in outdoor measurement facilities. This paper reports on the performance of these devices after 36 months of operation.

\section{EXPERIMENTAL SET-UP}

The Centre for Renewable Energy Systems Technology (CREST) has operated an outdoor monitoring system for photovoltaic modules since September 2000 (COMS). The outdoor measurement stand has since seen a complete upgrade, the transfer to which was completed in October 2002 (COMS2) and a further upgrade completed in February 2004 (COMS3). The system is described in detail in [1]. Data presented in this paper is all taken with data from COMS2 and above, as there are some inconsistencies to COMS1, but several of the modules were operated in this original system already and can thus be considered to be fully degraded at the start of this reporting period. The modules reported on here are listed in Table 1.

Most technologies are installed in duplicates in order to minimise the effects of failure of single modules. Some modules, however, are available in a single case only and one should keep in mind that any results might be a statistical one-off of the device under investigation. Even testing two supposedly identical devices showed significant differences between the samples, as demonstrated below.

\begin{tabular}{|cccc|}
\hline Technology & Samples & $\begin{array}{c}\text { Power } \\
{[\mathrm{Wp}]}\end{array}$ & $\begin{array}{c}\text { In- } \\
\text { stalled }\end{array}$ \\
\hline SJ - type 1 & SJ1, SJ2 & 4 & $07 / 2001$ \\
\hline SJ - type 2 & SJ3, SJ4 & 5.6 & $06 / 2001$ \\
\hline SJ - type 3 & SJ5, SJ6 & 4 & $07 / 2001$ \\
\hline DJ (a-Si/a-Si) & $\begin{array}{c}\text { DJ1, } \\
\text { DJ2 }\end{array}$ & 2.13 & $10 / 2002$ \\
\hline DJ (a-Si/ a- & DJ3, & 12.1 & $10 / 2002$ \\
DJGe & DJ & & \\
\hline $\begin{array}{c}\text { TJ (a-Si/a- } \\
\text { SiGe) }\end{array}$ & TJ1, TJ2 & 2.68 & $07 / 2001$ \\
\hline
\end{tabular}

Table 1: Summary of Devices (SJ - single junction, DJ - double junction; TJ - triple junction)

\section{SEASONAL PERFORMANCE}

Firstly, the seasonal performance is investigated in more detail. All measurements presented in the following are normalized to the value measured in the solar simulator in 2005. The monthly variation of the performance ratio is shown in Figure 1.

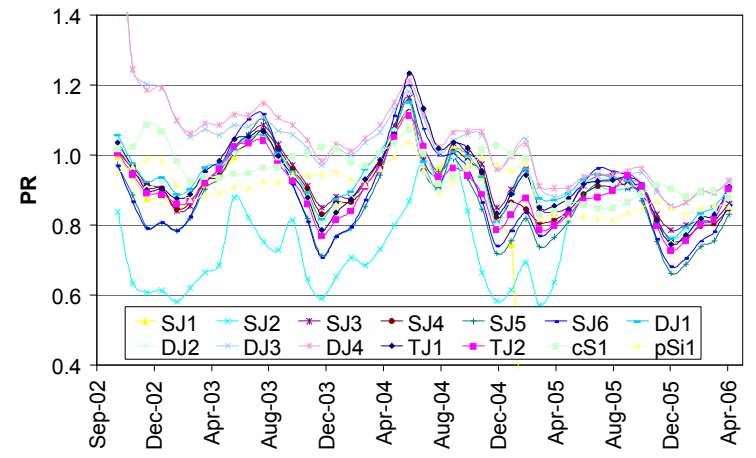

Figure 1: Monthly Performance Ratio of the devices under test

There appear to be three groups: one module is struggling, but recovers to normal performance in high irradiance conditions. This is due to a low shunt resis-

\footnotetext{
* corresponding author: Tel.: 01509-228148, Fax.: 01509-610031, email: R.Gottschalg@lboro.ac.uk 1-4244-0016-3/06/\$20.00 (2006 IEEE 
tance in this particular module. The multi-junctions all appear to be a bit high, but the solar simulator is known to overestimate the performance of these device categories due to the spectral mismatch between light source and realistic spectra [2]. Although the error is typically lower than the difference seen here. One can also discern the difference between the different years, with slight differences in the pattern between single and double junctions. Certainly the highest variations are seen in the single junctions, as for them the degradation/annealing cycle is more pronounced. One of the single junctions had an apparent problem after 18 months of operation.

The range of performance ratios is between 0.8 and 1.2 for all devices, with clear maxima in summer. The crystalline (c-Si) and poly-crystalline ( $p$-Si) devices, which are added for comparison, show an opposing trend.

The driving force between the devices is slightly different, though, which can be seen by using the monthly variation of the $I_{S C}$ normalized with the incident irradiance and the variation of the FF, which is shown in Figure 2 and Figure 3.

The seasonal variation of the ISc shows that the most significant changes are experienced by multijunction devices, specifically the triple junctions. This is largely due to changes in the junction matching due to varying incident spectra. This process is not as clear as it could be, e.g. using sunny data only would be much more obvious. Unfortunately, clouds affect the shape of the spectrum drastically, and hence the maximum of the Isc variation is shifted towards August/September, where the cells are warm. This increase in temperature is not too significant, though: the irradiance weighted temperature, which allows for the higher temperature at high irradiances, is in the worst case only $5^{\circ} \mathrm{C}$ different for months June and August/September, which is by no means enough temperature difference to explain this shift in the maximum.

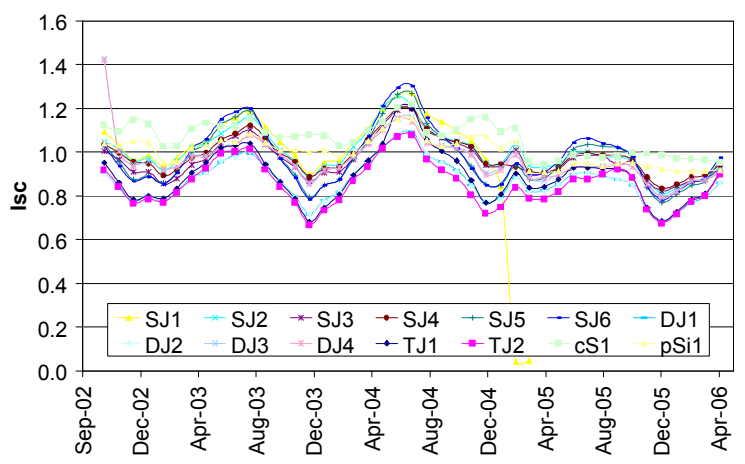

Figure 2: Monthly variation of the short circuit current divided by irradiance

The FF shows an even more obvious variation between multi-junctions and single junctions: the maximum of the normalized FF is shifted by about two months, still with a discernible maximum in the summer. The crystalline devices put in there for reference purposes show a much more stable behaviour with a minimum for the summer months. The magnitude FF of the multi-junction devices in particular is a side effect of the spectral mismatch in the solar simulator, which causes a change in the measured FF.

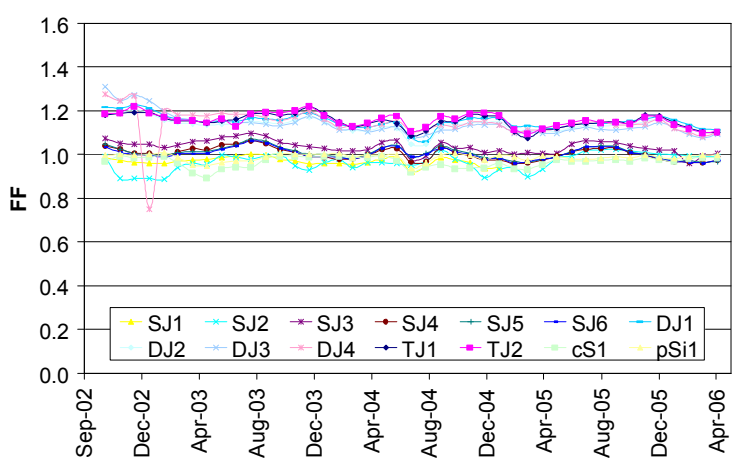

Figure 3: Variation of the monthly averaged FF (for irradiances above $50 \mathrm{~W} / \mathrm{m}^{2}$ )

The reason for this difference in behaviour is that single junctions are much more affected by the degradation/annealing pattern and the high temperatures in some months increase the annealing rate noticeably. In contrast, the multi-junction variation is driven by the Isc variation. The latter is of interest especially for countries in northern latitudes, where large variations in the incident spectrum are observed.

\section{ANNUAL PERFORMANCE}

The seasonal variation in the performance explains some of the reasons why modules behave differently. The monthly energy sums are obviously only of limited interest, because what counts is the long-term energy production. The main indicators here are the efficiency and the performance ratio of the devices, which are discussed below. There are some facts to note: the change over in the measurement system to COMS-3 brought a change in the reference pyranometer (Kipp \& Zonen CM11 to CM22) which brought some changes in the absolute efficiency determination, although the power rating did not change too significantly, i.e. that slight change in the performance is due to the difference in the monitoring device. There are also significant year-toyear changes, e.g. between 2003 and 2004 which were one of the worst and best years on record, respectively. The years 2002 and 2006 are not complete- only date form October 2002 - April 2006 is reported here.

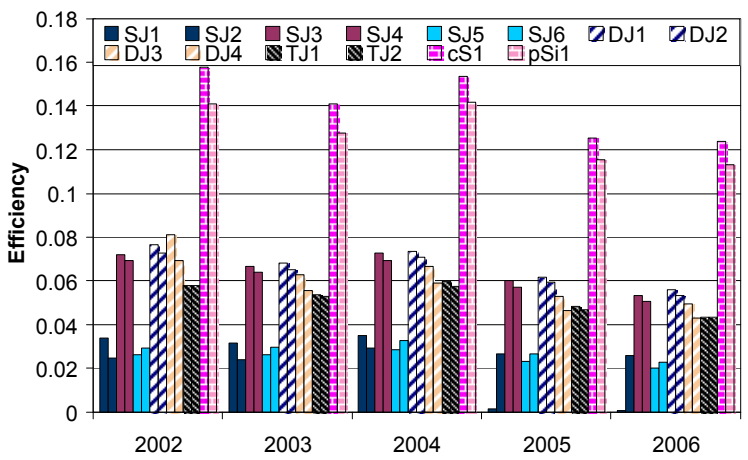

Figure 4: Annual Variation of the operating efficiency 
The efficiency of the a-Si devices varies from $2 \%$ to something close to $6 \%$. There is a slight degradation, but not more than for the c-Si device, which would indicate that there is no measurable long-term degradation and devices anneal back to stable performance levels or that there is no discernible long-term degeneration. The difference between the single and multi-junction devices in the overall performance is not too apparent, indeed the best performers in this particular field are one single junction device and one double junction device category.

There is also the suggestion of long-term degradation in the samples of e.g. the double junctions 1 and 2 . This is due to differences in the operating environment, because it could not be seen in the simulator measurements presented in Table 2, where the solar simulator measurements are summarized. There are slight differences in the temperature in the laboratory between measurements, so a slight variation in the calibration is to be expected, but even allowing for this specifically these two devices are measured with about $6 \%$ higher power rating in 2006 rather than 2005 . Thus this 'trendby-eye' is largely due to the year 2006 not being completed and a-Si devices have the highest performance in summer time- this is a side effect of reporting partial years only.

There is an astonishing difference in the years 2003 and 2004 for all devices. The operating efficiency improved for all devices $6-11 \%$ purely due to the difference in environmental conditions. The year 2004 was one of the worst on record while 2003 was one of the best years ever and devices benefited from the high operating temperature, which shifted the overall incident radiation profile much in favour of high irradiances in 2004. The multi-junctions could utilize this change in operating environment much more effectively than the single junctions.

There is a trend in the power rating given in Table 2 for single junction devices - they are measured with slightly lower power values in 2006 than they were in 2005. The multi-junctions, on the other hand, all show a slight increase in the power rating, in the order of $2-6 \%$. A deviation of about $2 \%$ is what would be expected from the Spire measurements and furthermore, the unit had to be moved and the re-calibration process is not yet completed, which might introduce a small decrease in the reproducibility (which is typically better than 1\%), but overall this trend cannot be explained that way.

It is unfortunate that from the 2006 measurements, only the SJ types 1 and 3 and the DJ type one would be within the manufacturers specified warranty rating. There is a very high absolute uncertainty in the rating of the triple junctions (and to some extent DJs) using the given measurement setup. Hence one cannot state categorically that the underperforming units are warranty cases, there might be a marginal overlap of the uncertainty margin with the $-10 \%$ which defines the warranty case, but overall this should not happen. This is due to the rating strategy of some manufacturers (see below) but also due to some production instabilities in earlier production cycles, reported e.g. [3], and newer devices of this particular manufacturer indeed perform better.
This efficiency variation is only one side of the coin, the biggest advantage of amorphous silicon is its often reported [4] improved specific energy yield. On the other hand, some less than ideal experiences have been reported [5]. This variation may be borne out partially already in the difference in the power and efficiencies reported, but is more apparent when normalizing to the rated power as shown in Figure 5.

\begin{tabular}{|c|c|c|c|c|}
\hline Technology & $\begin{array}{l}\text { Sam- } \\
\text { ples }\end{array}$ & $\begin{array}{l}\text { Rated- } \\
\text { Power } \\
\text { [Wp] }\end{array}$ & $\begin{array}{l}P_{\text {MPP }} \\
8 / 2005 \\
{[W p]}\end{array}$ & $\begin{array}{l}P_{\text {MPP }} \\
4 / 2006 \\
{[W p]}\end{array}$ \\
\hline SJ - type 1 & $\begin{array}{l}\text { SJ1, } \\
\text { SJ2 }\end{array}$ & 4 & $-/ 3.41$ & -13.5 \\
\hline SJ - type 2 & $\begin{array}{l}\text { SJ3, } \\
\text { SJ4 }\end{array}$ & 5.6 & $\begin{array}{ll}5.91 & I \\
5.76\end{array}$ & $\begin{array}{l}5.84 I \\
5.64\end{array}$ \\
\hline SJ - type 3 & $\begin{array}{l}\text { SJ5, } \\
\text { SJ6 }\end{array}$ & 4 & $\begin{array}{ll}2.42 & I \\
2.67 & \end{array}$ & $\begin{array}{l}2.31 / \\
2.59\end{array}$ \\
\hline DJ - type 1 & $\begin{array}{l}\text { DJ1, } \\
\text { DJ2 }\end{array}$ & 2.13 & $\begin{array}{ll}2.34 & I \\
2.30 & \end{array}$ & $\begin{array}{l}2.53 / \\
2.42\end{array}$ \\
\hline DJ - type 2 & $\begin{array}{l}\text { DJ3, } \\
\text { DJ4 }\end{array}$ & 12.1 & $\begin{array}{ll}9.68 & I \\
8.42 & \end{array}$ & $\begin{array}{l}10.08 / \\
8.63\end{array}$ \\
\hline TJ & $\begin{array}{l}\text { TJ1, } \\
\text { TJ2 }\end{array}$ & 2.68 & $\begin{array}{ll}2.11 & I \\
2.13 & \end{array}$ & $\begin{array}{l}2.17 I \\
2.19\end{array}$ \\
\hline
\end{tabular}

Table 2: Rated and Measured Power Values

The reference samples (c-Si/ pc-Si) sample perform very well in the given years, with the slight discontinuity between 2004/5 being due to the difference in irradiance sensor. Their performance ratio is about $90 \%$ in the last two years and slightly above unity before that. There are only two types of a-Si technologies, which can match that, one single junction type and one double junction type. There are two material types which underperform visibly, the single junctions type 1 and 2 . Out of the samples in type 1, one has failed already, which does not inspire confidence. These two types are also two companies who rate (or rated at the time) and sold their material as produced and not degraded, one even introducing a thermal annealing step to boost efficiency. The large differences between these materials and the rest are due to this difference in rating.

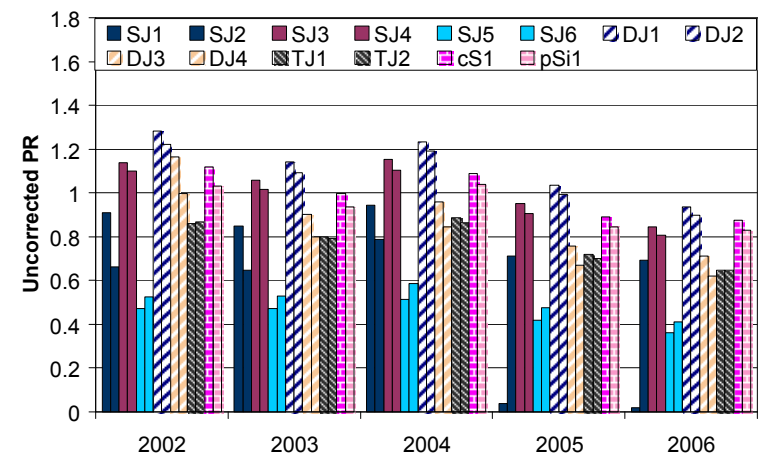

Figure 5: Annual Variation of the PR with respect to the rated power.

The performance of single junctions and multijunction is not really distinguishable; for all devices which attempt a post-degradation rating, the PR is in the $80 \%$ range, apart from the triple junction set in this test. There is a newer group of triple junctions in the system, 
which indeed performs better and thus the rather low performance of these samples can be put down to some of the earlier quality-instabilities also reported by others [3].

Thus it would appear that the specific energy yield of amorphous silicon is not higher than c-Si devices, or only in a very limited number of cases. However, so far this paper has reported a significant uncertainty in the manufacturer's rating and no noticeable long-term degradation of the devices. Hence, the energy yield should be evaluated using the power rating carried out in the laboratory. This is reported in Figure 6.

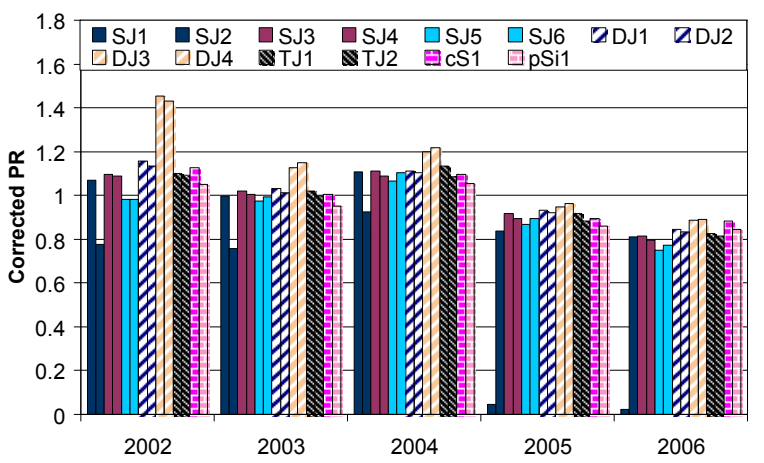

Figure 6: Annual Variation of the PR with respect to the rated power. Annual Variation of the PR with respect to the rated power

The comparison of performance has changed drastically. DJ3/4 show a significant degradation from year 2003 to 2004. This is expected, because these devices were installed as new in October 2004. Thus discussion is limited to the full years (as discussed earlier, 2006 only describes Winter months). There is not the significant difference between the devices, they are all pretty similar. There is one obvious failure, unfortunately for the much better device of the two single junction type 1s. However, this also shows how much variation of energy yield can be observed within one single batch of some manufacturers, with one device producing nearly $10 \%$ energy. This emphasizes the importance of using multiple devices in any energy rating study.

The single junctions and the triple junction seem to perform slightly worse than the double junctions in the maritime climate of the UK. The triple junctions are slightly worse, but still on par with the silicon reference devices. There are not enough different silicon devices to give rigorous proof of any improved energy yield of aSi devices over c-Si in general, but it appears that here the double junctions certainly fulfill this promise. None of the amorphous silicon devices show an energy production discernibly worse than the crystalline devices, though, even after being operational for several years. The triple junction might perform better in other locations, because of the wide variability of the spectrum [6], which has a completely different spectral energy distribution than sites with more clear sky days and further south. The susceptibility of the performance of triple junctions to spectral variations would inhibit the commonly reported performance advantage of these devices. The a-Si/a-SiGe device outperforms the other devices on that measure, which is an indication that a wider spectral response might favour improved energy production. However, in absolute terms, these devices would be warranty cases, as they degraded (as outlined in Table 2) to less then $10 \%$ below the manufacturers energy warranty. The improvement might even be more pronounced, as participation in a round robin test has shown that the power for a-Si devices is overestimated by several percent in CRESTs solar simulator, and correcting for this will enhance the PR further for any devices benefiting from this.

\section{CONCLUSIONS}

The results of a long-term measurement campaign of amorphous silicon modules was reported and compared with reference silicon modules. The major impact on the performance is identified as the rating of these devices, as - at least 5 years ago when this campaign was instigated - some manufacturers rate as manufactured rather than post degradation as it should be. Once devices are rated properly, their specific energy yield is in the same order of magnitude as silicon and could be better. There is a significant module-to-module variation, which makes a precise analysis difficult and only statistical comments can be made.

It is shown that in the maritime climate of the UK, different effects drive the seasonal changes in performance. Triple junctions are shown to be predominantly dominated by the spectrum while only about half the seasonal variation in single junctions can be attributed to spectral changes. The other half of the seasonal shift can be attributed to the annealing/degradation pattern which is well known.

\section{ACKNOWLEDGEMENTS}

The work at CREST is supported through the EPSRC Grant Nos GR/T03307/01 and GR/T03314/01

\section{REFERENCES}

[1] M. Bliss, et al., "Improved Outdoor Monitoring of Photovoltaic Modules", Proceedings of the 2nd Photovoltaic Science, Application and Technology, Loughborough, 2005, pp.

[2] T. R. Betts, et al., "Photovoltaic Performance Measurements in Europe: PV-Catapult Round Robin Tests", World Conference on Photovoltaic Energy Confersion, 4th, Waikaloa, US, 2006, pp. tb[

[3] M. Camani, et al., "Comparison and Behaviour of PV Modules", Proceedings of the 15th European Photovoltaic Solar Energy Conference, Vienna, 1998, pp. 2344-2349.

[4] C. Jardine and K. Lane, "PV-COMPARE: Energy Yields of Photovoltaic Technologies in Northern and Southern Europe", Proceedings of the Photovoltaic Science, Application and Technology Conference, Loughborough, 2003, pp. 42-47.

[5] A. J. Carr and T. L. Pryor, "A Comparison of the Performance of Different PV Module Types in Temperate Climates", Solar Energy, 76, 2004, pp. 285-294.

[6] T. R. Betts, et al., "Spectral Dependence of Amorphous Silicon Photovoltaic Device Performance", Photovoltaic Science, Application and Technology, Loughborough, 2003, pp. 127-132. 